\title{
Gestão de qualidade no setor de tintas imobiliárias: o estudo de caso da Tintas Coral
}

\author{
Quality management in the architectural coatings sector: the case study of Tintas Coral
}

Recebido: 20/10/2021 | Revisado: 25/10/2021 | Aceito: 28/10/2021 | Publicado: 31/10/2021

\author{
Ellysio Moreira Campos \\ ORCID: https://orcid.org/0000-0003-4906-1608 \\ Universidade Federal de Campina Grande, Brasil \\ E-mail: camposellysio2@gmail.com \\ Isabel Lausanne Fontgalland \\ ORCID: https://orcid.org/0000-0002-0087-2840 \\ Universidade Federal de Campina Grande, Brasil \\ E-mail: isabelfontgalland@gmail.com
}

\begin{abstract}
Resumo
Fundada em 1954, a Tintas Coral é uma empresa que está no mercado de tintas brasileiras a mais de 50 anos, com mais de 1.200 funcionários distribuídos em suas duas instalações. É reconhecida mundialmente pela excelência em inovação, tecnologia e satisfação de seus clientes. Desde 2008, pertence ao grupo holandês AkzoNobel, fundado em 1792, produtora de tintas e revestimentos com clientes em mais de 150 países e um grupo de 35.000 pessoas. Abordaremos, através da metodologia de estudo de caso, questões sobre os impactos que este segmento industrial pode causar (seja positivo ou negativo) no âmbito social e meio ambiente, além de conhecer as certificações de qualidade e políticas ambientais que a Tintas Coral apresenta, citando o resultado disto no mercado.
\end{abstract}

Palavras-chaves: Tintas; Meio ambiente; Certificações.

\begin{abstract}
Founded in 1954, Tintas Coral is a company that has been in the Brazilian paint market for over 50 years, with more than 1,200 employees distributed in its two facilities. It is recognized worldwide for excellence in innovation, technology and customer satisfaction. Since 2008, it belongs to the Dutch group AkzoNobel, founded in 1792, producer of paints and coatings with customers in over 150 countries and a group of 35,000 people.

We will approach, through the case study methodology, questions about the impacts that this industrial segment can cause (whether positive or negative) in the social and environmental scope, besides knowing the quality certifications and environmental policies that Tintas Coral presents, citing the result of this on the market.
\end{abstract}

Keywords: Paints; Environment; Certifications.

\section{Introdução}

Segundo a Associação Brasileira dos Fabricantes de Tintas (ABRAFATI, 2020), o segmento de tintas, no Brasil, engloba o conjunto dos cinco maiores do mundo. Dessa forma, contamos com um forte mercado frente à economia global. Os produtos que mais se destacam são as tintas imobiliárias, que lideram com 83,4\% o mercado nacional. Assim, tomemos este ramo específico para estudo neste artigo.

Para termos uma noção do grau de crescimento, ao longo dos anos, vejamos abaixo o crescimento das vendas em milhões/bilhões de litros de tinta vendidas entre 2001 a 2020. 
Figura 1 - Crescimento de venda de tintas no período de 200 à 2020.

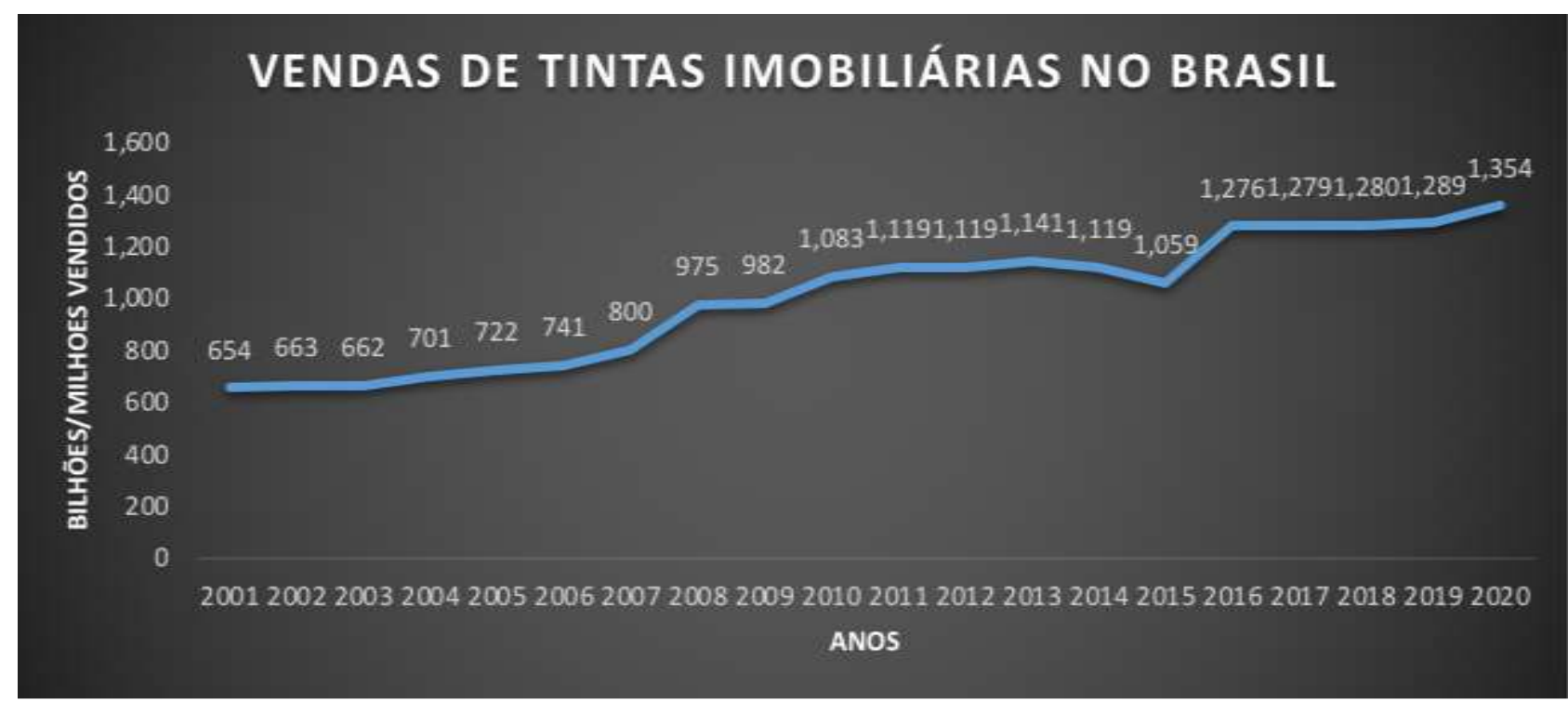

Fonte: Dados de Mercado, ABRAFATI 2020.

Durante o período de 2001 à 2020, o mercado de tintas imobiliárias obteve um crescimento de 207\%, um feito muito admirável, visto que o este mercado engloba todas as classes sociais e os mais distintos níveis de renda, assim, não depende de um "boom" na economia que alavanque as vendas, e sim, de suas inovações e movimentos que propiciem o consumo dos seus bens. Vejamos agora o comparativo de litros vendidos neste período em relação a tintas com outras finalidades.

Figura 2 - Comparativo de venda de tintas no período de 200 à 2020.

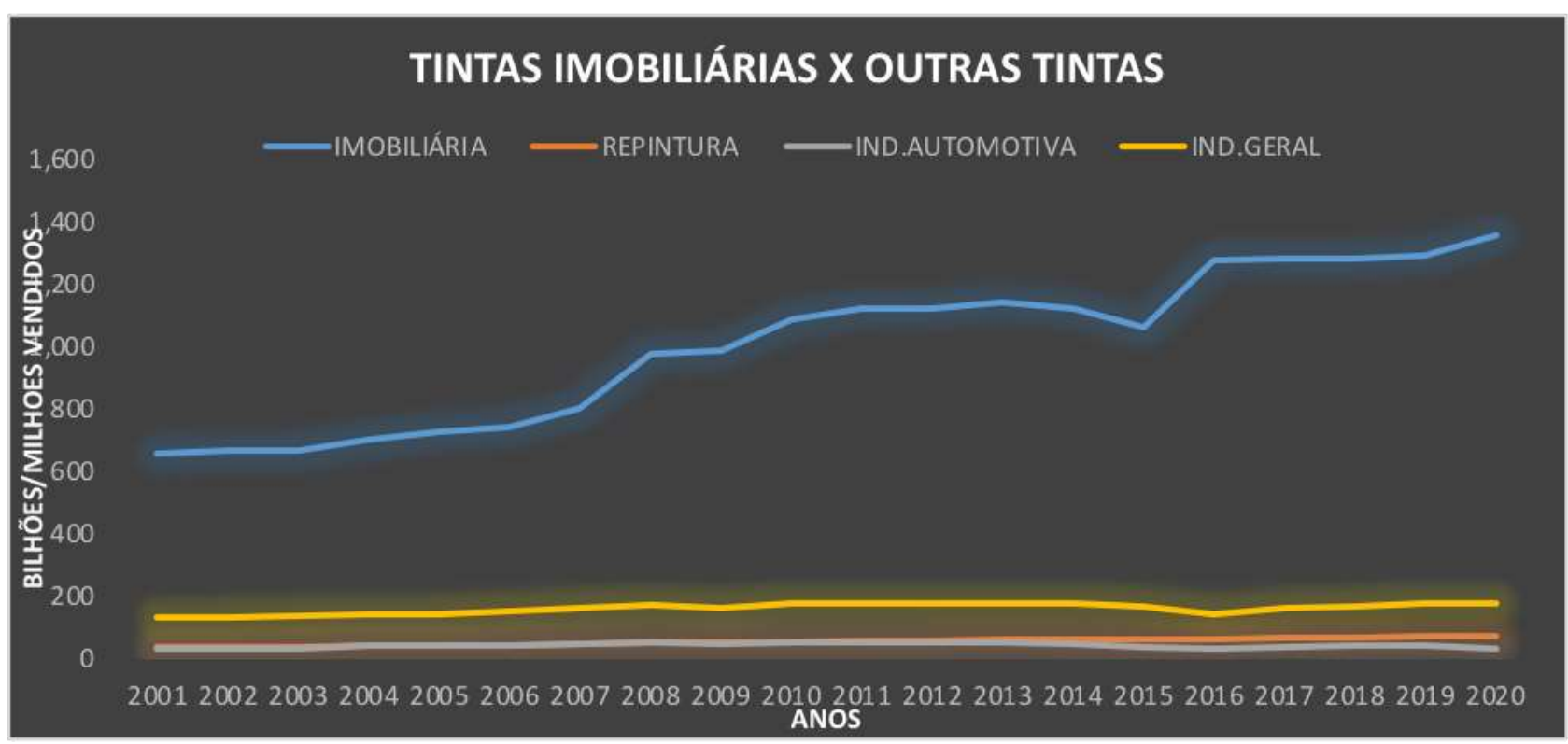

Fonte: Dados de Mercado - ABRAFATI 2020. 
Segundo Araújo (2015, P.4) muitas tintas com que pintamos paredes, tetos, portas, janelas e quase tudo que está ao nosso redor são altamente nocivas ao meio ambiente e, por conseguinte, também para a nossa própria saúde. Dada a proporção apresentada anteriormente, a afirmação de Kelson Araujo (ABRAFITI, 2020) faz com que se reflita sobre como está sendo o processo de fabricação de tintas domésticas e quais cuidados estão sendo tomados.

Partindo disso, o objetivo do presente trabalho é apresentar o estudo de caso da empresa Tintas Coral conforme informações levantadas nos sites da companhia e do grupo ao qual pertence, bem como demais fontes citadas nas referências.

\section{Metodologia}

Neste trabalho, utilizou-se por metodologia o estudo de caso descritivo, através da coleta de dados e informações afim de descrever conceitos de normas ambientais voltadas a empresa Tintas Coral. O estudo de caso consiste num método ou técnica de investigação, habitualmente utilizado nas ciências da saúde e sociais, que se caracteriza por exigir um processo de pesquisa e investigação, bem como a análise sistemática de um ou mais casos. De maneira simples, a MEC - Metodologia de Estudos de Caso, se aplica a todas as circunstâncias, situações ou fenômenos únicos sobre os quais se requer mais informação ou que merecem algum tipo de interesse dentro do mundo da pesquisa. Através deste, considerando o método qualitativo, será possível entender o porquê da inclusão de normas ambientais no histórico da empresa e, também, porque ela é um excelente exemplo para estudo de caso. Segundo Fontgalland (2021) a MEC oferece todas as condições de respostas aos objetivos bem como garante para futuros trabalhos um alicerce de partida.

\section{Tintas Coral}

Fundada em 1954, a Tintas Coral atua no mercado brasileiro a mais de 50 anos. Possui suas fábricas instaladas nas cidades de Mauá (São Paulo) e Recife (Pernambuco).

Figura 3. AkzoNobel. Instalação de Mauá, Rio de Janeiro.

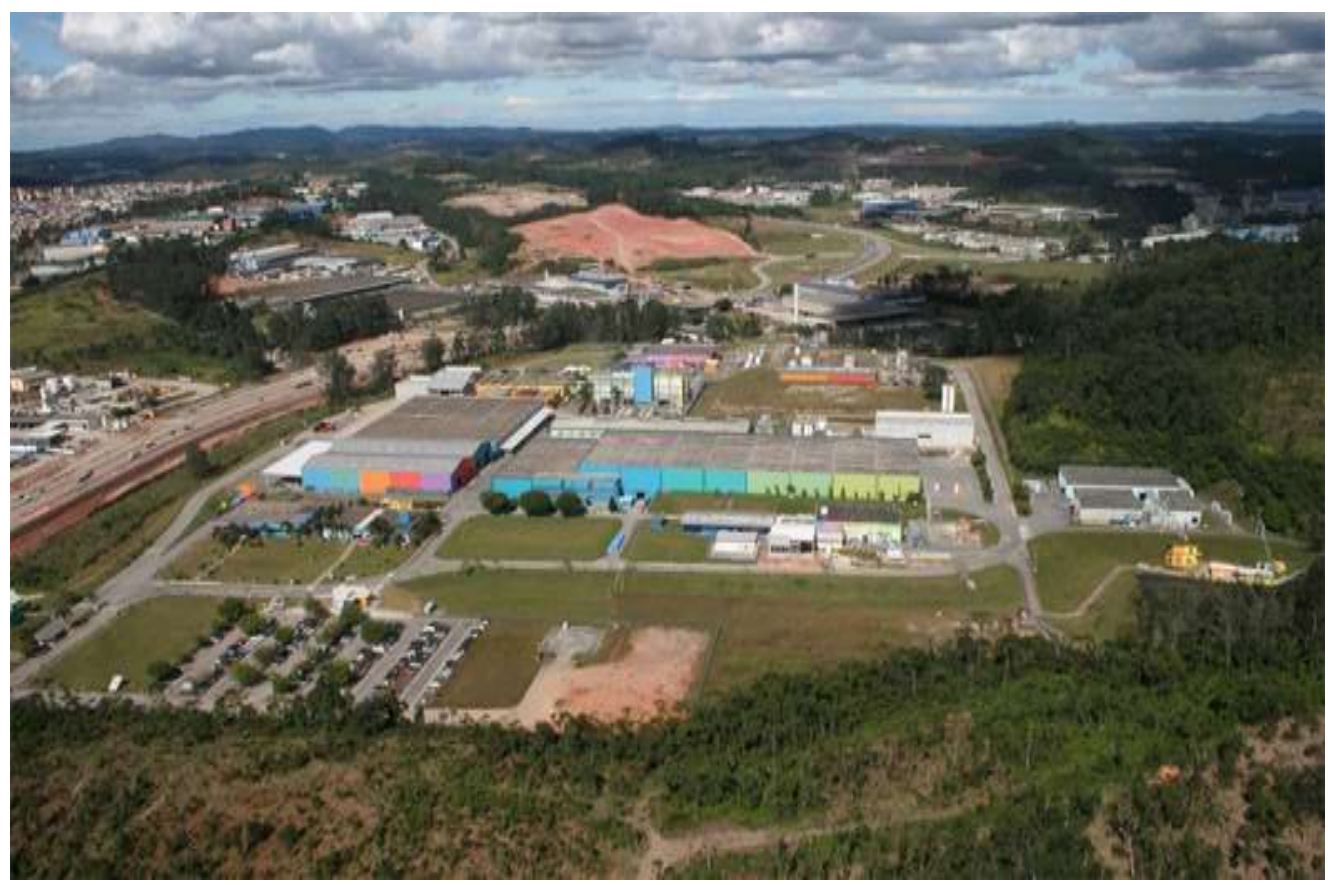

Fonte: AkzoNobel.com. 
A empresa Coral apoiada na importância da inovação e diversificação, em seu processo produtivo, oferece produtos e serviços inovadores, concentrando seus esforços na satisfação de todo público. É importante alertar que embora o alto grau de diversificação, foque em um único segmento: as tintas imobiliárias, torna-se prático segundo Britto (2013), que

do ponto de vista analítico, a complexidade do fenômeno da diversificação decorre precisamente do fato dele se constituir em um processo que se confunde com outras dimensões do crescimento empresarial, relacionadas às múltiplas dimensões das interações da empresa com o meio ambiente no qual está inserida" (BRITTO, 2013, p. 194).

O grau de P\&D empregado, no processo de fabricação das tintas, é muito elevado e propicia um portfólio de 2.016 tons nomeados. Isso otimiza a relação entre demanda-consumidor e dá praticidade às questões de instalações do tipo multipropósito, que é característico de indústrias químicas, além de se diferenciar dos concorrentes, pois conta com ferramentas que auxiliam na escolha e combinação de tonalidades, uma excelente demonstração dos aspectos relacionados a diversificação horizontal, visto que mantém proximidade do produto original e circula pelo canal de distribuição da companhia.

A Coral foi a primeira empresa brasileira a digitalizar tons para fabrico de suas tintas. Dada a amplitude dos impactos potenciais que a digitalização pode ter em uma organização e em todo o setor, não é surpreendente que existam várias definições diferentes do termo. A AkzoNobel viu na digitalização de três perspectivas: 1- A otimização de processos internos, o aprimoramento da colaboração com os clientes e novos modelos de negócios baseados em tecnologia digital, como por exemplo o desenvolvimento de aplicativos para revestimentos, adesivos e especialidades. 2- Do lado operacional, o cliente tem a experiência de criar implementar cores e texturas e 3- Impactos por meio de inovação de processo contínua puxada pelas atividades de digitalização das linhas de frente e de linha de fundo.

A digitalização envolveu na Coral, uma abordagem totalmente diferente e exigiu uma mudança em toda a organização e não apenas para a equipe responsável pela implementação da estratégia. TI, finanças, recursos humanos, marketing, compras, manufatura - todas as atividades são afetadas, portanto, a estratégia digital deve incorporar uma forte agenda de mudanças. Isso também estimulou, depois da pandemia do COVID-19, o aparecimento do Coral app, interface com as plataformas android/apple. Essa inovação incluí 240 cores e garante simulações com um arquiteto virtual que pode sugerir ao cliente combinações a partir das seleções disponíveis em ambiente real. Outra inovação, foi o simular de ambientes da Coral https://construcaoedesign.com/simulador-de-ambientes-da-coral/ que hoje atende mais de 4 milhões de usuários, nas regiões centrais do país, com visualização real 3D e permite total interação do cliente.

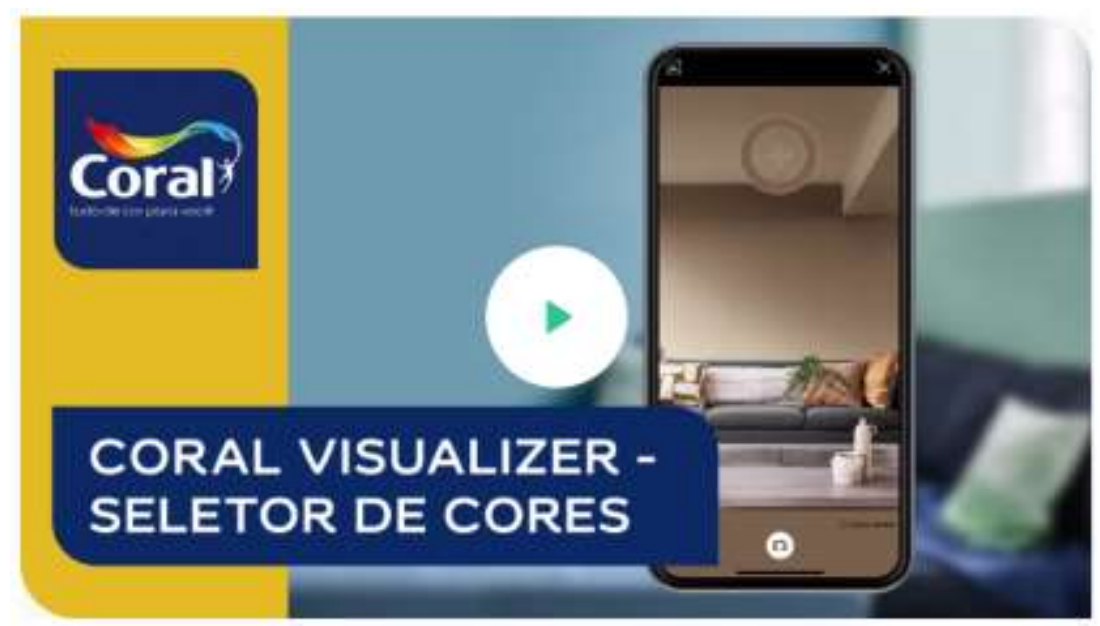

Fonte: Coral.com.br 


\section{Aspectos e Impactos ao Meio Ambiente}

É compreensivo que as indústrias são grandes contribuintes para a poluição e destruição do meio ambiente. E isso posto, na indústria de tintas, muitos são os elementos que afetam a natureza, sem levar em consideração a extraordinária quantidade de água e energia elétrica utilizada em seu processo de fabricação. Destaca-se aqui dois recursos, que passam por um momento delicado neste ano de 2021: as $\operatorname{VOCs}^{1}$ '(Volatile Organic Compounds), que ocorrem quando muitos processos químicos e movimentação de itens deixam resíduos pelo processo de produção e podem gerar danos ao meio ambiente; e a reciclagem de tons.

Entre as muitas ações que as empresas de ponta no setor de tintas estão implementando nos seus processos de fabricação de produtos para uso doméstico e industrial podemos destacar o compromisso das mesmas com o cumprimento dos regulamentos e das normas relativas à minimização do emprego de substâncias que exercem impacto sobre a saúde das pessoas e sobre o meio-ambiente, quais sejam os principais: chumbo e compostos orgânicos voláteis, conhecidos pela sua sigla em inglês VOC (Volatile Organic Compounds) (Araújo, 2015, P. 4).

- Na indústria de tintas: os matérias mais comum no processo são:

- No segmento de Papel, plástico e itens metálicos: os materiais utilizados para embalagens, etiquetagem e identificações tanto dos produtos quanto da matéria prima, que após o uso deve ser descartado corretamente ou até mesmo reutilizado e reciclado;

- No segmento químico: referente a toda matéria prima ou itens para limpeza, tais como resinas, solventes, diluentes, pigmentos, pós, material filtrante, VOC, etc. devem ser armazenados, manuseados e descartados com todo cuidado, qualquer descuido (principalmente dos químicos que se tornam vapor), podem proporcionar danos incalculáveis, seja material, seja operacional (saúde) ou ambiental.

- No processo produtivo como um todo: Envolvem tanto a saúde dos colaboradores quanto a qualidade para o meio ambiente. Um sistema de produção falho poderá gerar muito mais emissores de gases no ar, muito mais ruídos dentre outros diversos.

Com todos estes aspectos e ainda a busca por padrões para impedir incidentes, ocorrem questões de sustentabilidade e impactos ao meio ambiente que não podem deixar de ter espaços neste mercado, pois, tratam-se de produtos químicos. A fim de sanar estes problemas e, ao mesmo tempo, garantir uma melhor produtividade e rentabilidade para a firma, através de gestão de qualidade e marketing sustentável, foram criadas as ISO’s, que são uma das maiores organizações mundiais de padrões e, as técnicas PmaisL ${ }^{2}$. No ramo das tintas imobiliárias, uma associação de suas produtoras as normas técnicas e movimentos de qualidade, bem como reutilização de matérias primas no processo, tornam-se bem vistas pela sociedade e propiciam um desenvolvimento mais sustentável, prolongando sua permanência no mercado e garantindo uma melhor utilização dos recursos escassos.

\section{Certificações}

Partindo para a associação aos padrões de qualidade e políticas ambientais, a Tintas Coral se destaca bastante neste segmento, desde em questões de pioneirismo, quanto em questões de acumulação e atualização de certificações. Através destes programas de qualidade, é notável que a empresa possui responsabilidade ambiental, cuidados com seus produtos, preocupação em redução de poluentes, minimização de impactos negativos ao meio ambiente, saúde e qualidade de vida dos colaboradores. Todos estes fatores são pontos chaves na fidelização de clientes e garantem uma margem de lucro maior.

\footnotetext{
${ }^{1}$ Sigla para compostos orgânicos voláteis.

2 Sila para produção mais limpa.
} 
Uma empresa que se preocupa com tais pontos fundamentais, possui uma responsabilidade muito além de "lucro a qualquer custo", é algo que chama atenção sobre o humanismo incorporado na atividade fabril. A política ambiental portanto é

o conjunto de metas e instrumentos que visam reduzir os impactos negativos da ação antrópica - do homem - sobre o meio ambiente. Como toda política, possui justificativa para sua existência, fundamentação teórica, metas, instrumentos e prevê penalidades para aqueles que não cumprem as normas estabelecidas. Interfere nas atividades dos agentes econômicos e, portanto, a maneira pela qual é estabelecida influencia as demais políticas públicas, inclusive as políticas industrial e de comércio exterior. Por outro lado, as políticas econômicas favorecem um tipo de composição da produção e do consumo que tem impactos importantes sobre o meio ambiente. (LUSTOSA \& YOUNG, 2013, P. 341).

Diante disto, vejamos o portfólio que a Tintas Coral apresenta sobre estas políticas que a tornam uma referência para o mercado.

\subsection{ISO 9001}

A Tintas Coral foi pioneira brasileira (em seu segmento) a conseguir, em 1993, a ISO 9001, e em 1994, todas as instalações brasileiras possuíam a normal que define os requisitos para colocar um sistema de gestão da qualidade, que em 2015 sofrera uma atualização para se contextualizar a novas realidades.

Esta norma anexa um melhoramento nas informações das empresas, cadeia de suprimentos, otimização de processos e agilidades em desenvolvimento dos produtos. A partir desta, o processo busca enxugar desperdícios e utilizar melhor de seus recursos, utilizando todo o potencial da cadeia produtiva.

\subsection{ISO 14001 e OHSAS 18001}

Em 2013, a AkzoNobel adiciona certificação em suas instalações nas áreas de Gestão de Saúde, Segurança e Meio Ambiente, ou seja, inclui no seu histórico a ISO 14001:2004, voltada a questões de gestão, controle e supervisão ambiental, e a OHSAS 18001:2007, voltada a segurança e saúde ocupacional. Ambas destacando o olhar da companhia para o meio ambiente e seus colaboradores, sendo novamente destaque nos quesitos sociais.

\subsection{Atualização das certificações}

Com o passar dos anos, as normas de qualidade vão se atualizando e, com isto, as empresas preocupadas em manter o controle de qualidade se atualizam também, assim fez a Tintas Coral com a ISO 9001:2015 e ISO 14001:2015, para as atualizações de 2015 e também para as atualizações de 2020, sendo a ISO 9001:2020 e a ISO 14001:2020. Ainda em 2020, não foi apenas as atualizações das certificações que impressionam, mas também a obtenção da ISO 45001:2018, norma voltada a segurança do trabalho local, loco regionais e global, sendo assim, mais uma prova do comprometimento da empresa em manter a saúde de seus colaboradores, e como a própria Tintas Coral fala ${ }^{3}$, ela está empenhada em fabricar tintas de maneira sustentável, com o menor impacto possível ao meio ambiente e sem riscos à saúde dos consumidores e colaboradores.

\subsection{Tudo de cor}

Não é só através de certificações que a Tintas Coral demonstra interesse e preocupação com a natureza e questões sociais, em 2009, foi criado o movimento Tudo de Cor, que promove o uso de produtos à base de água afim de reduzir o impacto ao meio ambiente e promover causas sociais, cujo objetivos ${ }^{4}$ são:

\footnotetext{
${ }^{3}$ Citação pega na página oficial da Tintas Coral, encontrada no link https://www.coral.com.br/pt/sobre-nos

${ }^{4}$ Dados retirados do Manual tudo de Cor. O guia de engajamento social (e de pintura) da Coral, Pág. 13 e 17, 2021.
} 
- Engajar e estimular a pintura como um ato de cidadania;

- Promover a autoestima individual e coletiva;

- Promover a capacitação de pintores;

- Impactar socialmente a vida dos brasileiros;

- Contribuir para que as cidades e comunidades sejam mais sustentáveis e;

- Valorizar a arte pública.

Saindo um pouco do ambiente interno para o externo, propiciando uma corrente do bem via capacitação profissional, aplicação de produtos de qualidade e deixando sua marca por todo o Brasil.

\section{Resultados e Discussão}

Nota-se que o mercado de tintas imobiliárias atraí um mercado de grande potencial e conta com um impacto social, ambiental e inovador muito expressivo. É compreensivo que, de tal maneira, a inclusão de políticas de gestão ambiental, na companhia e a reutilização de embalagens e matéria prima seja muito bem aceita no ramo social, principalmente fora dos muros empresariais.

É impressionante a quantidade de tons que a Tintas Coral apresenta bem como todas as ferramentas e projetos que auxiliam na escolha dos mesmos, tornando sua atividade muito diversificada e arrojada. Não é de se estranhar que em um mercado que apresentou $207 \%$ de crescimento em um período de 20 anos. É bastante comprometida com qualidade e nos mostra, com orgulho, todas as certificações e atualizações para manter seu padrão.

Segundo a Abrafiti (2021), desde sua fundação em 1985, "o estímulo à pesquisa e ao desenvolvimento tecnológico sempre ocupou papel central em sua atuação, assim como o incentivo à produção e à disseminação de conhecimentos" do segmento em geral. Baseado no tríplice projeto da Associação: o Congresso Internacional de Tintas (realizado em conjunto com a Exposição de Fornecedores), o Curso de Tecnologia em Tintas e o Prêmio Abrafiti de Ciência em Tintas, a Coral engajou-se à promover uma linha de profissionalização de pintores certificados, o que tem sido um dos carro-chefe de alcance social.

\section{Considerações Finais}

As tintas domésticas atuam, não somente como tintas para se pintar, mas como cores que podem mudar o meio onde são aplicadas. Um ambiente colorido e personalizado detém o poder de transformar o humor das pessoas, e assim, trazer personalidade. A Coral Tintas tem por missão: levar cor para a vida das pessoas e em cima desse slogan abriu-se todo um mercado pautado em personalizar cada cliente. As ferramentas que auxiliam nas escolhas, como o toner computer design e um conjunto de políticas ambientais que fixa seu nome no mercado, fizeram toda a diferença no decorrer dessa última década de transformação.

Por mais desafiador que tenha sido, a mudança para a digitalização, foi essencial para o sucesso no futuro. As tecnologias digitais criaram possibilidades que nunca existiram antes. E isso oportunizou para a Coral e todos os participantes existentes na indústria de tintas que vieram depois, influenciar o Market-Share de outros segmentos como o de revestimentos e pisos cerâmicos que crescerem e criarem valor agregado. Isso também, abriu uma porta para a entrada de concorrentes inovadores que nunca participaram do mercado antes.

Ao analisar a Tintas Coral, foi possível observar que a aplicação de políticas de gestão de recursos fêz a diferença em um sistema produtivo de alto nível. A qualidade com o processo, desde a introdução de matéria prima até a entrega do produto são destaques que propiciam o crescimento corporativo. Saber aproveitar os recursos, armazenar e descartar os resíduos, cuidar 
de todo o sistema para evitar poluentes é algo que faz a diferença e reduz custos, e isto é muito visível na citada empresa.

Constatou-se por fim, que a Coral é uma das melhores empresas no segmento de tintas do mundo, além de um símbolo em gestão ambiental. A empresa possui extremo potencial para o futuro, e não é exagero falar que no Brasil se tem um excelente exemplo industrial que propicia ótimos cases para estudos em economia, quer seja industrial, quer seja ambiental.

\section{Referências}

ABNT. Norma brasileira. ABNT NBR ISO 14001 (2021a). Disponível em http://www.madeira.ufpr.br/disciplinasghislaine/iso-14001-2004.pdf

Akzonobel. Marcas e negócios (2021a). Disponível em https://www.akzonobel.com/en/countries/akzonobel-brasil/nossas-marcas-e-negocios.

Akzonobel. Sobre nós (2021b). Disponível em https://www.akzonobel.com/en/countries/akzonobel-brasil/sobre-nos.

Akzonobel. Página inicial (2021c). Disponível em https://www.akzonobel.com/en.

Akzonobel. AkzoNobel Brasil (2021d). Disponível em https://www.akzonobel.com/en/countries/akzonobel-brasil

Abrafati. O setor de tintas no Brasil. Disponível em https://abrafati.com.br/o-setor-de-tintas-no-brasil/

Researchgate. Panorama do setor de tintas no Brasil: mercado, gestão e tecnologias para o segmento de tintas imobiliárias. Disponível em https://www.researchgate.net/publication/327733597_Panorama_do_setor_de_tintas_no_Brasil_mercado_gestao_e_tecnologias_para_o_segmento_de_tintas_i mobiliarias

ABNT. ABNT Catálogo (2021b). Disponível em: http://www.abnt.org.br/.

ARAUJO. Kelson. Iniciativas Mundiais de Vanguarda para a Sustentabilidade no Setor de Tintas. 2015.

FONTGALLAND, I (2021) SLIDES MEC, repositório UFCG.

Governo do estado de São Paulo. GUIA TÉCNICO AMBIENTAL TINTAS E VERNIZES - SÉRIE P+L Tintas e Vernizes. São Paulo, 2008.

KUPFER, D. \& HASENCLEVER, L. Economia industrial: Fundamentos teóricos e políticas no Brasil. 2 ed. Rio de Janeiro: Elsevier Editora Ltda, 2013.

MOLINARI. M. A., QUELHAS. O.L.G., \& PEREIRA DO NASCIMENTO FILHO. A. Avaliação de oportunidades de produção mais limpa para a redução de resíduos sólidos na fabricação de tintas. 2013.

SESI. Norma ISO 45001 - Sistema de gestão de segurança e saúde no trabalho. https://www.sesi-ce.org.br/blog/norma-iso-45001-sistema-de-gestao-deseguranca-e-saude-do-trabalho/

TINTAS CORAL. Manual tudo de cor: O guia de engajamento social (e de pintura!) da Coral. https://www.coral.com.br/pt/tudo-de-cor-para-voce.

TINTAS CORAL. https://www.dropbox.com/s/qo8iiiif5nomyro/Certificados.zip?dl=0

TINTAS CORAL. Coral inspira (2021d). https://www.coral.com.br/pt/inspiracao-de-cor.

TINTAS CORAL. Bem-vindo ao nosso mundo de cores (2021a). https://www.coral.com.br/.

TINTAS CORAL. Encontrar produtos (2021b). https://www.coral.com.br/pt/resumo-do-produto

TINTAS CORAL. Quem somos (2021c). https://www.coral.com.br/pt/sobre-nos

TEMPLUM. ISO 9001 - Sistema de gestão da qualidade. https://certificacaoiso.com.br/iso-9001/ 